\title{
Strategies for a Small to Medium-sized Enterprise to Engage in an Existing Ecosystem Ermela Bashuri and Tony Bailetti
}

\author{
"Strategy is about making choices, trade-offs; it's about deliberately choosing \\ to be different." \\ Michael E. Porter \\ Professor at Harvard Business School
}

\begin{abstract}
Recent advances in ecosystem theory prescribe that companies need to develop offers that are modular and form unique or supermodular complementarities with other offers. However, both academic and managerial knowledge of the strategies that especially small and medium sized enterprises (SMEs) can use to engage in existing ecosystems for value creation remains scattered and predominantly vague. This article thus aims to explore applicable ecosystem engagement strategies from the perspective of SMEs, as discussed in previous scholarly literature. In so doing, the article puts forward and elaborates three distinct strategies that SMEs can apply to become part of value-creating ecosystems. In this way, the findings contribute to the literature on ecosystems.
\end{abstract}

\section{Introduction}

Recent advances in ecosystem theory prescribe that small and medium sized enterprises (SMEs) need to develop offers that are modular and form complementarities with other offers that are unique or supermodular (Jacobides et al., 2018). Supermodular complementarity takes place when "more of A makes B more valuable". For example, the more widespread availability of applications increases the value of an operating system, and the ever-larger number of operating system installations increases the value of those applications (Jacobides et al., 2018). However, SME strategies to engage with ecosystems do not always seem to incorporate what theory prescribes. SMEs are therefore too often left without understanding how to engage with ecosystems in a manner that provides them value. One of the challenges that SMEs face when trying to engage in an existing ecosystem is the lack of an explicit process that guides them on how to engage in an existing ecosystem.

Hence, this article aims to explore applicable ecosystem engagement strategies from the perspective of SMEs. Specifically, the article follows the widely used knowledge translation approach (see Dal Mas et al., 2020) to review previous literature on ecosystems. As a result, the article suggests: 1) a strategy for a SME to engage in an ecosystem that builds on ecosystem theory as articulated by Jacobides et al. (2018), 2) a strategy for a SME to engage in an ecosystem based on a summative model that synthesizes findings from literature review, and 3) a strategy for a SME to engage in an ecosystem based on the concept of Minimum Viable Footprint (MVF) advanced by Adner (2012). In this vein, the article contributes to the extant body of literature on SME engagement in ecosystems by discussing three alternative engagement strategies.

The article is structured as follows. First, it reviews previous literature on ecosystem types and related key components. Then, it discusses reasons and prerequisites for collaboration in ecosystems. Thereafter, the article elaborates on ecosystem engagement strategies and their success factors, and presents three different ecosystem engagement strategies for SMEs. Finally, the article concludes by summarizing the results, discussing the implications for theory and practice, as well as providing limitations of the study and future research avenues. 


\section{Strategies for a Small to Medium-sized Enterprise to Engage in an Existing}

\section{Ecosystem Ermela Bashuri and Tony Bailetti}

\section{Ecosystem Types and Components}

Adner (2017) defines an ecosystem as "the alignment structure of the multilateral set of partners that need to interact for a focal value proposition to materialize". What makes an ecosystem powerful is its ability to create and deliver dominant value propositions through interorganizational collaboration. Ecosystem participants mutually influence each other because of simultaneously existing interdependencies and complementarities (Jacobides et al., 2018; Kaapor, 2018; Baumann, 2019; Autio \& Thomas, 2020).

Ecosystem research can be organized by its focus into three distinct streams: 1) business ecosystems, 2) innovation ecosystems, and 3) platform ecosystems (Jacobides et al., 2018). A business ecosystem is comprised of a set of partners that contribute to the value proposition of the ecosystem's focal firm (Baumann, 2019). An innovation ecosystem is anchored on the innovation that enables customers to use the end-to-end product, with a functional goal to enable technology development and innovation (Jackson, 2011; Jacobides et al., 2018). It includes three sub-ecosystems: science, technology, and business innovation (Xu et al., 2018). Finally, a platform ecosystem is comprised of a platform and the applications that interoperate with it (Tiwana, 2014). There are two types of platform ecosystems: 1) innovation platforms and 2) transactional platforms (Cusumano, 2019).

While innovation platforms serve as technological building blocks that both platform owner and other ecosystem actors can share to build new complementary products and services, transaction platforms serve as intermediaries or online marketplaces that enable businesses and people to buy, sell and access a variety of goods and services (Cusumano, 2019). Of note, some platform ecosystems can be a hybrid of the two types. Overall, the key components that exist in ecosystem types include: 1) keystone, 2) complementors, 3) complementarities, 4) resources, 5) activities, 6) value proposition, 7) governance, 8) customer, and 9) others (Jacobides et al., 2018).

\section{Keystone}

Playing a key role in ecosystem regulation, the keystone is the most significant member of an ecosystem (Weber \& Hine, 2015). The keystone's actions influence the success of all ecosystem members (Mäkinen \&
Dedehayir, 2012). An ecosystem's keystone makes a set of trade-offs favorable to complementors, by 1) attributing the added value to the complementor that generates it, 2) building and structuring complementarities between ecosystem members, 3) stimulating complementarity investments, 4) reducing transaction costs, 5) promoting flexibility, and 6) designing value capture tools for all ecosystem members (Marty \& Warin, 2020). Moreover, the number of keystone players in a specific industry has a high impact on an ecosystem's innovation rate, as the industry is likely to obtain a higher innovation rate with multiple keystone players (Marty \& Warin, 2020).

\section{Complementors}

Complementors are ecosystem actors that produce modules which contribute to the focal offer's value system (Kapoor, 2018). In this vein, complementors have a key role in facilitating and promoting the focal firm's product, and for providing complementary products and solutions to the end-user (Rong et al., 2013). Complementors are obliged to innovate continuously, be connected, and develop a recognizable brand to help the focal offer succeed (Worner et al., 2019). Subsequently, the focal firm needs support and commitment from complementors to commercialize its products; meaning, the success of the focal firm's product commercialization may largely depend on the complementors' efforts (Rong et al., 2013).

\section{Complementarities}

Complementarities are products or services that are sold separately but used together, each creating value for the other (Kapoor \& Lee, 2012). Complementors in an ecosystem create value by dealing with unique or supermodular complementarities that are non-generic (Jacobides et al., 2018). Unique complementarities are complementarities that lead to co-specialization, for example, complementarities that require each other, while supermodular complementarities increase the value of each other. For example, a variety of apps increases the value of an operating system (OS), and vice versa, thus yielding higher returns (Jacobides et al., 2018).

\section{Resources}

The resources of the ecosystem enable the interaction of actors and enable them to create value (Talmar et al., 2020; Weber \& Hine, 2015). There are different types of resources, including "intangible" resources such as knowledge and information, cultural and social capital, 


\section{Strategies for a Small to Medium-sized Enterprise to Engage in an Existing}

\section{Ecosystem Ermela Bashuri and Tony Bailetti}

access to important social relationships, specific skills and capabilities, as well as "tangible" resources including, for example, financial resources, human resources, along with novel technologies and services (for example, wireless technology, web services, cloud technology) (Battistella et al., 2013).

\section{Activities}

Activities in ecosystems are considered as the mechanisms by which an actor generates its productive contribution to the ecosystem (Talmar et al., 2020). For example, an actor's ability to create value from a new technology depends on the accompanying changes by ecosystem complementors that may need to adapt their activities for the new technology to be successfully commercialized (Kapoor \& Lee, 2012). According to Battistella et al. (2013), technologies typically constitute the necessary tools through which an ecosystem's activities can be deployed.

\section{Value proposition}

The ecosystem's value proposition is "the intended value arising from the system-level overarching offering by the supply-side agents in the ecosystem" (Talmar et al., 2020). In accordance, Frow et al. (2014) stress that in an ecosystem, value proposition is "a shaper of resource offerings", as it positions a firm in a market by highlighting their favourable points of difference compared to competitors, determining their promises of delivered value to customers in terms of benefits and price, and forming a foundation for a supply-eustomer relationship.

\section{Governance}

What makes ecosystems distinct from other arrangements is the non-hierarchical structure of governance. The non-hierarchical structure of shared governance rights and control ensures that the ecosystem keystone acts in the interest of overall ecosystem actors. That said, Adner (2017) notes that while the keystone often sets and enforces the governance rules, it ultimately reaps the lion's share of gains after the ecosystem is aligned. Nonetheless, Koch and Kerschbaum (2014) found that developers in technology industries tend to perceive their ecosystem and its governance as an important whole, rather than as hardware, software, marketplace, and other aspects separately.

\section{Customer}

Ecosystem customers (or end-customers) represent the variety of requirements from the demand side and tend to "assemble" the offers of different suppliers and other ecosystem actors (Rong et al., 2013). That is, customers in ecosystems can choose among the components of an offer that are supplied by each participant, and can also, occasionally, choose how the offers are combined (Jacobides et al., 2018). In some cases, a customer may even become themself a producer, sometimes referred to as a "prosumer" (Battistella et al., 2013; Leminen et al., 2015).

\section{Others}

Business, innovation, and platform ecosystems can also include other components and intermediaries, such as suppliers, system integrators, distributors, operators, advertisers, finance providers, universities, research institutions, regulatory authorities, government agencies, standard-setting bodies, and the judiciary (Mäkinen \& Dedehayir, 2012; Battistella et al., 2013; Rong et al., 2013).

\section{Reasons for SMEs' Ecosystem Collaboration}

SMEs wish to engage in ecosystems to create and capture value in effective ways (Kapoor, 2018; Zhu, 2019). Davidson et al. (2014) note that, while "in traditional markets, value creation is incremental as organizations typically cover costs plus some return on assets, in ecosystems, organizations create value through their engagement within the ecosystem". Ecosystem actors are thus simultaneously influenced by their own capabilities and by their interactive ties with other players in the ecosystem (Heikkilä \& Kuivaniemi, 2012). SMEs in an ecosystem are therefore not just interconnected with each other, but indeed also depend on each other to develop mutual benefits.

To make their engagement in an ecosystem beneficial not only for themselves but for all participants alike, SMEs need to consider how to help others in the ecosystem create value (Heimala, 2020). Being part of an ecosystem requires co-developing or co-evolving (Moore, 2006), value co-creation (Ritala et al., 2020), and collaboration with other ecosystem members. In ecosystems, collaboration and competition occur simultaneously. Thus, SMEs engaging in ecosystems may also have the opportunity and/or need to collaborate with their direct and indirect competitors to achieve mutually beneficial outcomes (van Angeren et al., 2013). 


\section{Strategies for a Small to Medium-sized Enterprise to Engage in an Existing}

\section{Ecosystem Ermela Bashuri and Tony Bailetti}

\section{Reasons for actor collaboration in ecosystems}

Ecosystems are built on voluntary collaboration and strategic interactions between independent actors (Pidun et al., 2020). Ecosystem actors, such as SMEs, collaborate with each other mainly for the following reasons:

- Collaboration to bundle additional functionalities to the core ecosystem offer: In a platform ecosystem, for example, platform sponsors and complementors collaborate to bundle additional functionalities to the core platform as a way to enhance its value by creating complementary technologies (Agarwal \& Kapoor, 2018)

- Collaboration to share resources and take advantage of network synergy: SMEs engaged in an ecosystem collaborate together to share information or resources and also to complement each other with products and technologies, thereby taking advantage of the network synergy (Tang \& Qian, 2020)

- Collaboration to complement offerings: In this type of collaboration, SMEs engaged in an ecosystem collaborate mainly with complementors that provide complementary products, which are customized or compatible with a focal product (innovation) or platform (Tang \& Qian, 2020)

- Collaboration to commercialize products: Ecosystem actors engage in this type of collaboration when they wish to commercialize complementary products that were previously released for free (Eckhardt et al., 2018)

- Collaboration to build capabilities: Ecosystems enable SMEs to access and share resources and collaborate to build capabilities that were previously cost-prohibitive (Tata Consultancy Service, 2019). For example, digital technologies help organizations in ecosystems to collaborate and build new capabilities or products or to help in further advancements in science and technology (Ringel et al., 2019)

\section{Prerequisites of Ecosystem Engagement}

The ecosystem keystone has a key role in attracting SMEs and other actors to engage in an ecosystem, by creating a compelling image of the future ecosystem, and by clearly defining the ecosystem value proposition and associated structures of governance and interaction (Dattée et al., 2018). A SME wishing to join an ecosystem needs to both fulfill certain prerequisites and, at the same time, strategize their mode of entry in an ecosystem. The key prerequisites are 1) having a modular or non-generic complementarity (Jacobides et al., 2018), 2) technological compatibility with other ecosystem complementors, 3) developing the right capabilities for digital partnering, and 4) adopting an ecosystem mindset.

\section{Modularity and complementarity}

To successfully engage in an ecosystem, a SME needs to produce a modular part that complements other parts, which are then offered together as a whole to a customer (Jacobides et al., 2018). Customers expect a value proposition focused on their needs, not the offerings of individual SMEs that they must piece together themselves (Jacobides, 2019). SMEs need to make their offerings modular to allow "inter-firm offer modularity" (Schilling, 2000). This will allow customers to increase the range of possible product combinations that they can make by combining components from a variety of complementors.

\section{Technological compatibility}

If a SME wants to join a platform ecosystem, they need to make sure that they have the necessary technological compatibility to complement and gain access to offerings of other ecosystem complementors. Technology compatibility is often a prerequisite for gaining access to the complements of other ecosystem complementors, and it also increases a SME's ability to appropriate the returns from the innovation (Ceccagnoli et al., 2012).

\section{Developing the right capabilities for digital partnering} Developing the right capabilities for digital partnering is key for getting value from an ecosystem. To create digital partnering, a SME needs digital readiness that consists of three key characteristics: 1) being distinctive, 2) being digitally organized, and 3) being open (Sebastian et al., 2020). Digital partnering requires SMEs to leverage data analytics and create operation models that are optimized for partnering with ecosystem partners that operate in a digital environment (Sebastian et al., 2020).

Adopt an ecosystem mindset

SMEs that wish to engage in an ecosystem need to have 


\section{Strategies for a Small to Medium-sized Enterprise to Engage in an Existing}

\section{Ecosystem Ermela Bashuri and Tony Bailetti}

an ecosystem mindset and make an ecosystem engagement objective part of their scaling masterplan. Adopting an ecosystem mindset requires shifting from profit-focused strategy to purpose-focused strategy, from strictly competition to cooperation with competition, from subcontracting and risk-sharing to partnering and opportunity-sharing, and from owning to sharing resources with other ecosystem complementors (Ritala et al., 2013).

\section{Success Factors of Ecosystem Engagement}

While ecosystem engagement strategies help SMEs thrive, they are also effective in promoting joint learning, making an ecosystem more efficient in innovating, and allowing a higher degree of flexibility by enabling partners to constantly adjust their activities to changing circumstances (Williamson \& De Meyer, 2020). In fact, ecosystem strategies have even more to offer, given that "actions required to grow a SME's revenue and to implement growth formulas can greatly benefit from embracing the business ecosystem approach" (Bailetti, 2010). That said, ensuring an ecosystem's engagement strategy success becomes essential for SMEs in joining an ecosystem.

Previous literature on ecosystems suggests that SMEs need to do the following to ensure that their engagement strategy is successful:

\section{Provide modular and non-generic} complementarities (Jacobides et al., 2018; Talmar et al., 2020). SMEs should modularize their offer so that it can complement other ecosystem products or services that customers are going to consume (Jacobides et al., 2018). Moreover, to become part of an existing ecosystem SMEs need to customize their offering so that the complementarity they provide is non-generic (Talmar et al., 2020).

2. Adopt a standardized interface (Schilling, 2000). SMEs should adopt a standardized interface that makes their product compatible with the components of other SMEs. Such SMEs can employ inter-SME product modularity that enables customers to assemble their own multivendor configuration (Schilling, 2000).

\section{Balance specializations trade off within and across} ecosystems: Ecosystem complementors that focus on a specific product category (that is, category specialization) can scale by engaging in various ecosystems, while ecosystem complementors that are specialized in many products and or services can scale better by engaging in one ecosystem only (Tavalaei \& Cennamo, 2020).

\section{Ensure alignment with ecosystem's focal value} proposition: Complementors must align their strategies with objectives and value propositions set by a focal SME in the ecosystem and, at the same time, ensure a unique value proposition to create a distinct position from other ecosystem members (Tavalaei \& Cennamo, 2020).

\section{Focus on a narrowed segment to achieve competitive advantage: Complementors can achieve distinctiveness in an ecosystem by focusing on a narrowed segment of the market within the platform ecosystem (Moore, 2006).}

\section{Adopt an outward-facing culture: Participating in} an ecosystem requires an outward-facing culture and the ability to manage relationships with a host of complementors (Jacobides, 2019).

Engagement strategies in the existing ecosystem context A successful engagement in an ecosystem is not about what a SME does with its offer, but rather how that SME brings to the table all the other complements it needs to succeed. "Technological integration" and "partnerships" with other complementors seem to be the two main ways SMEs prefer to use as entry strategies for an existing ecosystem. Technological integration with existing ecosystem complementors suggests that small complementors can engage in an existing ecosystem by increasing specialization and technological integration with existing complements in the ecosystem, thereby benefiting from their established reputation (Van Angeren et al., 2013). On the other hand, new entrants need to choose between entering alone or partnering and cooperating with a local partner (Estrin, 2019). Partnerships play a great role in helping SMEs overcome societal grand challenges such as health (for example, COVID-19), global warming, water shortage, energy concerns, emissions, and poverty. These societal grand challenges cannot be addressed by one SME alone, but rather require a collaborative approach (De Stobbeleir, 2020) and cross-sectorial partnerships with partners from different industries to develop innovative solutions (Doh et al., 2019). 


\section{Strategies for a Small to Medium-sized Enterprise to Engage in an Existing}

\section{Ecosystem Ermela Bashuri and Tony Bailetti}

\section{Strategies for SMEs to Engage in Existing Ecosystems}

This section suggests three strategies that SMEs can follow to engage in an existing ecosystem. These strategies include, 1) a strategy for a SME to engage in an ecosystem that builds on ecosystem theory as articulated by Jacobides et al. (2018), 2) a strategy for a SME to engage in an ecosystem based on a summative model that synthesizes findings from literature review, and 3) a strategy for a SME to engage in an ecosystem based on the concept of Minimum Viable Footprint (MVF) advanced by Adner (2012).

\section{1) Ecosystem engagement strategy for a SME based on the ecosystem theory (cf. Jacobides et al., 2018)}

Jacobides et al. (2018) define ecosystems as "distinct forms of organizing economic activities that are linked by specific types of complementarities." Subsequently, a SME's engagement strategy in an existing ecosystem consists of mapping complementarities both in production and in consumption. Complementarities in production happen when offers by existing ecosystem complementors complement the ecosystem's focal offer (ecosystem focal value proposition) by adding more value to it. Complementarities in consumption happen due to choices by customers who combine the ecosystem's focal offer (ecosystem focal product/service) with complements from individual complementors. The constructs of this engagement strategy are illustrated in Figure 1 and elaborated thereafter.

- Complementarities. According to Jacobides et al. (2018), "ecosystems are groups of firms that must deal with either unique or supermodular complementarities that are non-generic". Thus, creating offers that directly complement an ecosystem's focal offer or other ecosystem complementors' offers enables SMEs to connect to the ecosystem's focal innovation provider either directly or indirectly. Given that complementarities help to jointly add value to customers, SMEs should offer products and services that are either unique (that is, the ecosystem offer requires the SME's offer) or supermodular (meaning, the SME's product or service offer makes the ecosystem offer more valuable).

- Modularity. Creating a modular offer (that is, an offer that can be combined with other ecosystems offers) enables SMEs that want to engage in an existing ecosystem to easily interconnect their offer with the offer of other ecosystem complementors in pre-defined ways. Modularity also facilitates mapping of complementarities in consumption by enabling customers to choose and bundle together among components offered by different complementors whose offers are bound together by interdependencies.

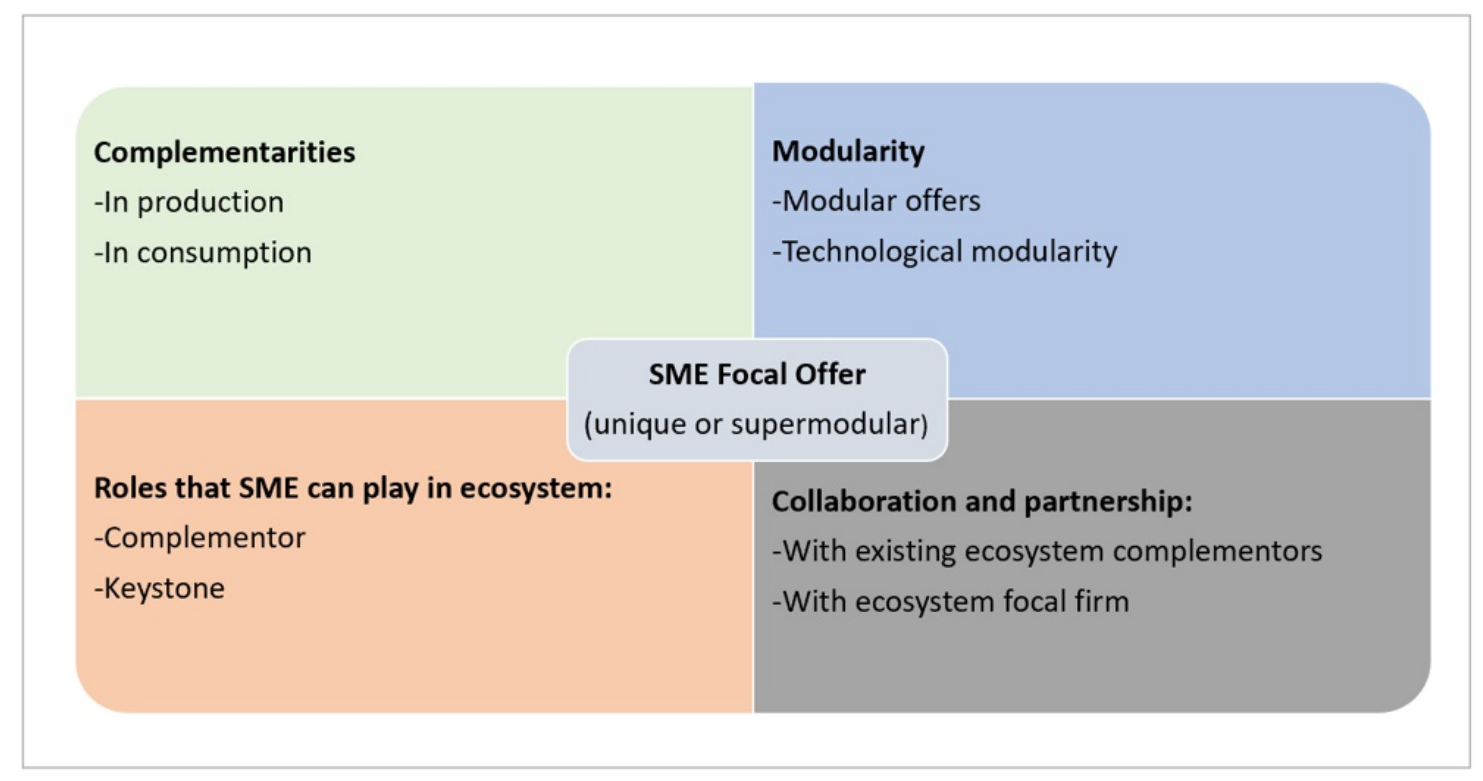

Figure 1. Ecosystem engagement stategy based on Jacobides et al. (20218) 


\section{Strategies for a Small to Medium-sized Enterprise to Engage in an Existing}

\section{Ecosystem Ermela Bashuri and Tony Bailetti}

- Collaboration and partnerships. SMEs need to establish partnerships and collaborate with existing ecosystem actors to interact with them and commercialize together offers that benefit the end customer. Technological modularity is a key element in enabling collaboration and coordination between SMEs and other ecosystem complementors.

- Role that a SME should play in the existing ecosystem. To successfully execute their ecosystem engagement strategy, SMEs should secure their role in a competitive ecosystem. A SME should assess whether it can join an ecosystem as a complementor or as a keystone that can shape the rules in the existing ecosystem. The latter is more difficult to achieve because to become an ecosystem keystone and prime mover of an existing ecosystem, an SME needs a superior product or service that is hard to replicate (Jacobides, 2019). For this reason, the common strategy mainly proposes SMEs to join as complementors.

\section{2) Ecosystem engagement strategy based on a model that} synthesizes findings from the literature.

The strategy described in this section is based on a model that more widely synthesizes findings from literature on ecosystems, representing the views of multiple authors. The proposed model (Figure 2) has three building blocks: 1) a SME's entry strategy, 2) outcomes of the entry strategy, and 3) ecosystem attributes that produce these outcomes. These building blocks are further elaborated after the illustration.

The synthesized model is based on five "ecosystem attributes" that consist of the following:

- Ecosystem type. In a digital world of connected interdependencies, firms need to analyze the ecosystem in which their product or service will operate. Before engaging in an ecosystem, a SME should decide on the ecosystem type they should engage to better strategize their ecosystem entry strategy.

- Ecosystem shared objective. Given that ecosystems are purpose-oriented, SMEs that want to engage in an existing ecosystem should make sure that what they will offer to an ecosystem is in alignment with the ecosystem's shared objective.

- Number of dominant players. The theory prescribes that ecosystems with more than one keystone player tend to be more innovative. Thus, if a SME

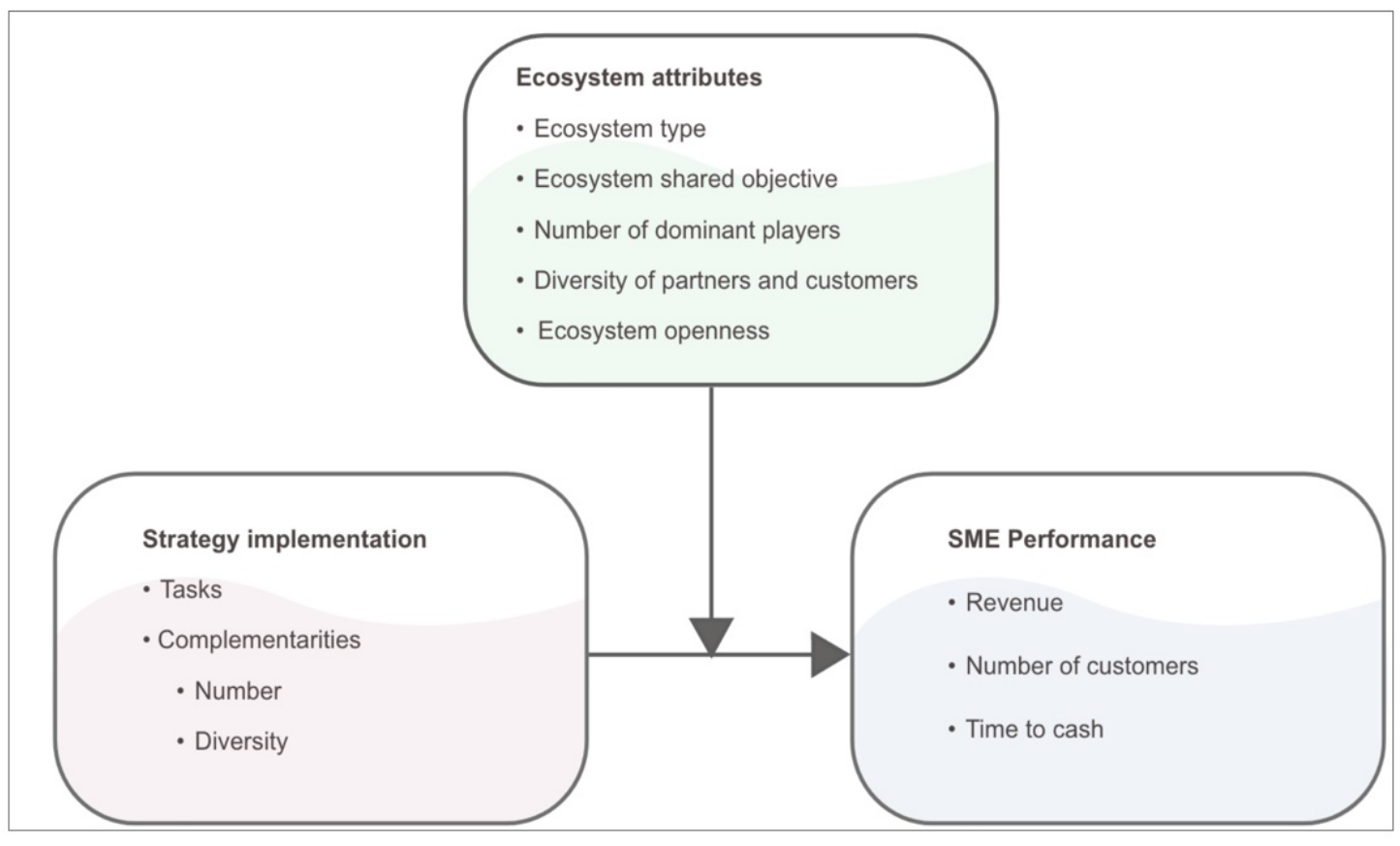

Figure 2. Model that describes what a SME needs to do to strategize its entry into an ecosystem. 


\section{Strategies for a Small to Medium-sized Enterprise to Engage in an Existing}

\section{Ecosystem Ermela Bashuri and Tony Bailetti}

strives for innovation, it should probably look for ecosystems with more dominant players as keystones.

- Diversity of partners and customers. The more diverse an ecosystem is in terms of partners and customers, the more opportunities a SME can find for partnerships and collaboration. Further, diversity of partners and customers contributes positively to innovativeness.

- Ecosystem openness. Ecosystem openness has a great impact on a SME's entry strategy. An open ecosystem provides complementors with increased flexibility to engage in innovation and operations, while closed ecosystems tend to have tighter rules of engagement that ask for approval (Jacobides, 2019).

Regarding the outcomes, or the "SME's performance", the synthesized model focuses on three key performance indicators (KPIs), namely revenue, the number of customers, and time to cash. Finally, ecosystem "strategy implementation" is conceptualized to have two building blocks: 1) complementarities and 2) tasks sequence.

- Complementarities. Collaborating with existing ecosystem complementors is one of the strategies that SMEs can follow to engage in an ecosystem (Jacobides et al. 2019). A company that wants to join an ecosystem needs to start small to demonstrate impact in the ecosystem by integrating with existing ecosystem complementors to benefit from their established relationship, and then grow. If the SME holds an IP protected complementarity, the best approach to engage in an ecosystem is to establish partnership with a large complementor that could buy into it (Jacobides et al., 2019). Another option of selling a unique and supermodular complementor is by joining the ecosystem as a certified complementor solution provider to conform to a series of quality specifications in product design, and to pass a rigorous certification process conducted by the platform owner (Ceccagnoli et al., 2012). Table 1 shows six complementarities that can be grouped into unique and supermodular in accordance with the theory of ecosystems (see Jacobides et al., 2018).

- Engagement strategy tasks: Table 2 displays a list of engagement strategy tasks that a SME should perform to make its ecosystem engagement successful and achieve the desired outcome.

3) Ecosystem engagement strategy for a SME based on the Minimum Viable Footprint

Adner (2012) proposes that to successfully build value in an ecosystem, SMEs should follow a step-by-step approach and build initial value by using an ecosystem Minimum Viable Footprint (MVF) approach. This approach consists of "the smallest configuration of elements that can be brought together and still create unique commercial value" (Adner, 2012; Leavy, 2012). After building the MVF, the SME can use it as a base for enhancing the ecosystem's focal value proposition. In this vein, the MVF-based strategy allows SMEs to begin with a subset of problems that they are better positioned to solve and that ensure the highest level of ecosystem

Table 1. Diversity of complementarities based on Jacobides et al. (2018).

\begin{tabular}{|l|l|l|}
\hline $\mathbf{N r}$ & Complementarity & Type \\
\hline 1 & $\begin{array}{l}\text { More of X's product makes SME's product more } \\
\text { valuable }\end{array}$ & Supermodular \\
\hline 2 & More of SME's product makes X more valuable & Supermodular \\
\hline 3 & SME's product requires X's product & Unique \\
\hline 4 & X's product requires SME's product & Unique \\
\hline 5 & X's product and SME's product require each other & $\begin{array}{l}\text { Unique (co- } \\
\text { specialization) }\end{array}$ \\
\hline
\end{tabular}




\title{
Strategies for a Small to Medium-sized Enterprise to Engage in an Existing
}

\author{
Ecosystem Ermela Bashuri and Tony Bailetti
}

Table 2. Engagement strategy tasks to achieve a SME's performance objectives

\begin{tabular}{|c|c|c|c|c|}
\hline $\mathrm{Nr}$ & Task & Expected outcome & $\begin{array}{l}\text { Required } \\
\text { complementor(X) }\end{array}$ & Complementarity \\
\hline 1 & Market research & $\begin{array}{l}\text { Identify the ecosystem } \\
\text { the SME should interact } \\
\text { with }\end{array}$ & $\begin{array}{l}\text { Intermediary } \\
\text { /Internal Sales } \\
\text { team }\end{array}$ & $\begin{array}{l}\text { SME's product } \\
\text { requires X's } \\
\text { services (Unique) }\end{array}$ \\
\hline 2 & $\begin{array}{l}\text { Engage in } \\
\text { ecosystem with } \\
\text { multiple keystone } \\
\text { players }\end{array}$ & - Higher innovativeness & $\begin{array}{l}\text { Ecosystem } \\
\text { keystone }\end{array}$ & $\begin{array}{l}\text { Interacting with } \\
\text { more keystone } \\
\text { players makes } \\
\text { SMEs innovate } \\
\text { more and their } \\
\text { products more } \\
\text { valuable } \\
\text { (Supermodular) }\end{array}$ \\
\hline 3 & $\begin{array}{l}\text { Make your offer } \\
\text { compatible with } \\
\text { ecosystem shared } \\
\text { objective }\end{array}$ & $\begin{array}{l}\text { - Access to many } \\
\text { customers } \\
\text { Increased chances to } \\
\text { collaborate and partner } \\
\text { with existing ecosystem } \\
\text { actors }\end{array}$ & $\begin{array}{l}\text { Ecosystem focal } \\
\text { value proposition }\end{array}$ & $\begin{array}{l}\text { SME's product } \\
\text { requires integration } \\
\text { with ecosystem } \\
\text { focal product or } \\
\text { service to provide a } \\
\text { joint IP solution } \\
\text { (Unique) }\end{array}$ \\
\hline 4 & $\begin{array}{l}\text { Provide a joint IP } \\
\text { solution }\end{array}$ & $\begin{array}{l}\text { Integrating with } \\
\text { platform solutions } \\
\text { Increase the total value } \\
\text { to the customer beyond } \\
\text { the existing solutions by } \\
\text { integration }\end{array}$ & Platform owner & $\begin{array}{l}\text { Existing ecosystem } \\
\text { complementor's } \\
\text { product and SME's } \\
\text { product necessitate } \\
\text { each other (Unique) }\end{array}$ \\
\hline 5 & $\begin{array}{l}\text { Establish } \\
\text { partnership with } \\
\text { existing } \\
\text { ecosystem } \\
\text { players }\end{array}$ & $\begin{array}{ll} & \text { Lower entry barrier } \\
\text { - } & \text { Co-create to leverage } \\
\text { continuous innovation } \\
\text { - Share resources and } \\
\text { capabilities } \\
\text { - Bridge a capital gap in } \\
\text { SME's capabilities } \\
\end{array}$ & $\begin{array}{l}\text { Existing ecosystem } \\
\text { complementors }\end{array}$ & $\begin{array}{l}\text { Existing ecosystem } \\
\text { complementor's } \\
\text { product and SME's } \\
\text { product necessitate } \\
\text { each other (Unique) }\end{array}$ \\
\hline 5 & $\begin{array}{l}\text { Invest in novel } \\
\text { technologies and } \\
\text { AI }\end{array}$ & $\begin{array}{l}\text { - Gain competitive } \\
\text { advantage } \\
\text { - Stay ahead of the game }\end{array}$ & $\begin{array}{l}\text { AI solution } \\
\text { providers }\end{array}$ & $\begin{array}{l}\text { More of AI and } \\
\text { novel technology } \\
\text { makes SME's } \\
\text { product more } \\
\text { valuable } \\
\text { (Supermodular) }\end{array}$ \\
\hline 6 & $\begin{array}{l}\text { Sell to existing } \\
\text { ecosystem } \\
\text { customers or } \\
\text { complementors }\end{array}$ & $\begin{array}{ll}\text { - } & \text { Generate revenue } \\
\text { - } & \text { Increase customer base }\end{array}$ & $\begin{array}{l}\text { Customers and } \\
\text { existing ecosystem } \\
\text { complementor }\end{array}$ & $\begin{array}{l}\mathrm{X} \text { and SME require } \\
\text { market transactions }\end{array}$ \\
\hline
\end{tabular}




\section{Strategies for a Small to Medium-sized Enterprise to Engage in an Existing}

\section{Ecosystem Ermela Bashuri and Tony Bailetti}

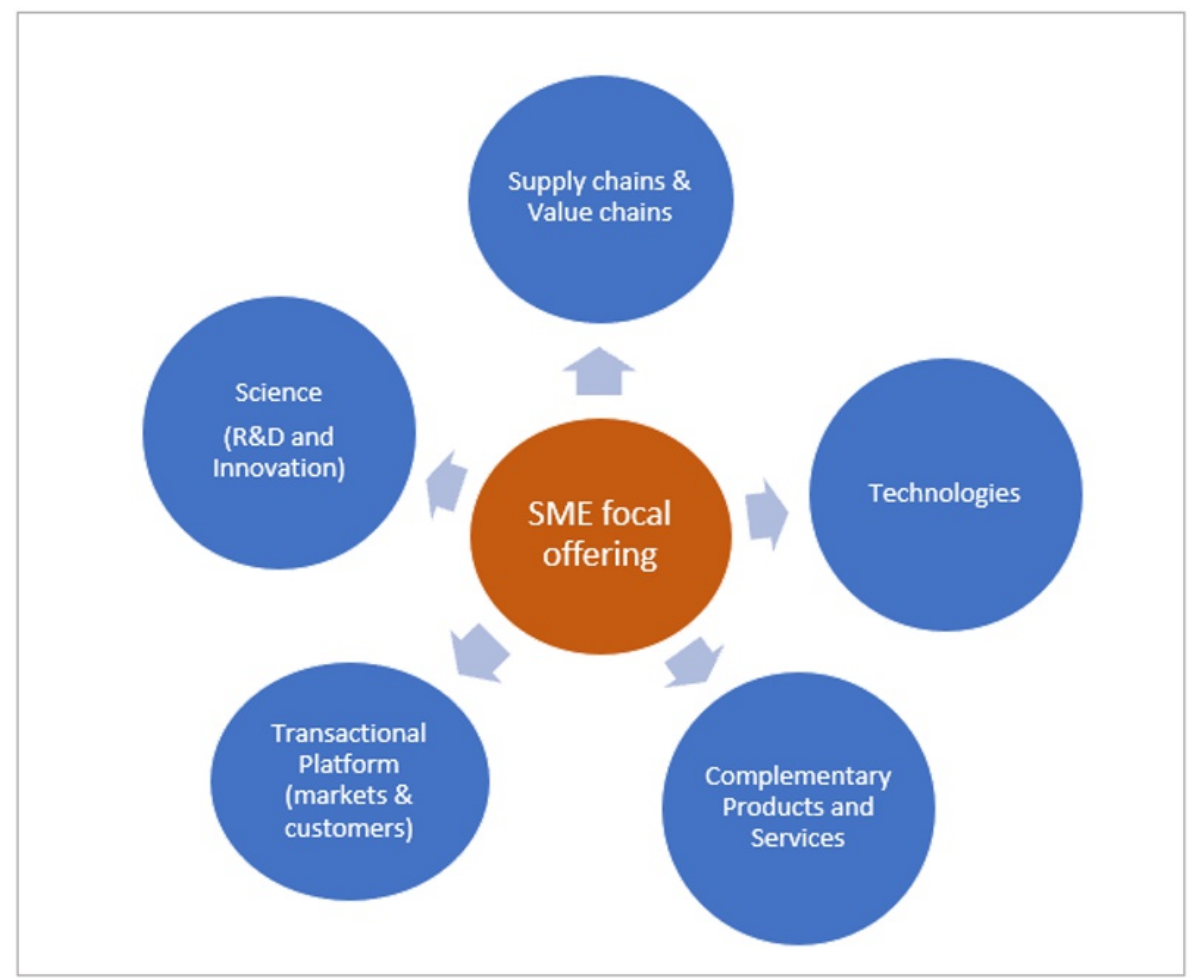

Figure 3. Sub-ecosystems that an SME can engage in based on its focal offer and desired outcomes

partners' motivation (Adner, 2012). This enables SMEs to strategize their ecosystem engagement with a limited scope (Heising et al., 2021) that seeks to achieve full scale by quickly establishing a dense network of partners and customers. In later phases, the SME can expand their value proposition by collaborating with new complementors. Overall, the MVF strategy is essentially a sub-ecosystem engagement strategy based on the SME's focal offer and the outcomes it wants to gain from engaging in a specific ecosystem (Figure 3 ).

A SME can create an ecosystem MVF by engaging in any of the following sub-ecosystems of an existing ecosystem:

- Supply chains and value chains sub-ecosystem: An SME should engage in this sub-ecosystem if its focal offer is related to accelerating digital transformation in logistics or creating value-added services.

- Technologies sub-ecosystem: In this case, a SME's engagement in the ecosystem consists in providing foundational technologies to the existing ecosystem.
- Complementors sub-ecosystem: In this case, the SME joins an ecosystem as a complementor by providing complementary products or services that complement (complete or bring to perfection) one or more existing products or services in the existing ecosystem.

- Transactional platform sub-ecosystem: Transactional sub-ecosystems are characterized by a central platform (for example, Amazon, Alibaba, Trip Advisor, and Google Play) that links independent producers of products and services with independent customers. In this type of subecosystem, value creation is driven by the number of successful transactions (Pidun \& Reeves, 2019). SMEs should engage in such an ecosystem when their intent is purely transactional, to buy or sell by getting access to the platform's existing market and customers. In this case, the SME's engagement in an ecosystem is low and the company is not significantly dependent of others in the ecosystem.

- Science sub-ecosystem: SMEs should engage in a science sub-ecosystem of an existing innovation ecosystem when their focal offer is 1 ) $R \& D$ services 


\title{
Strategies for a Small to Medium-sized Enterprise to Engage in an Existing
}

\author{
Ecosystem Ermela Bashuri and Tony Bailetti
}

\begin{tabular}{|c|c|c|c|c|}
\hline $\begin{array}{l}\text { 1.Identify a gap in the } \\
\text { existing ecosystem }\end{array}$ & $\begin{array}{l}\text { 2.Develop an offer that } \\
\text { addresses the gap }\end{array}$ & $\begin{array}{l}\text { 3.Identify the sub- } \\
\text { ecosystem you should } \\
\text { engage in }\end{array}$ & $\begin{array}{l}\text { 4.Identify the sub- } \\
\text { ecosystem actors you } \\
\text { need to partner with }\end{array}$ & $\begin{array}{l}\text { 5. Establish } \\
\text { collaboration and } \\
\text { partnership }\end{array}$ \\
\hline $\begin{array}{l}\text { Identify a subset of } \\
\text { ecosystem problems that } \\
\text { you are better positioned to } \\
\text { solve. }\end{array}$ & $\begin{array}{l}\text {-Develop your capabilities to } \\
\text { remove ecosystem pain } \\
\text { points. } \\
\text {-Develop an offer that } \\
\text { addresses the identified } \\
\text { ecosystem problems. } \\
\text {-Develop a value proposition } \\
\text { that ensures the highest level } \\
\text { of ecosystem ecosystem } \\
\text { partners' motivation. }\end{array}$ & $\begin{array}{l}\text { Choose one of the following } \\
\text { sub-ecosystems where you } \\
\text { can better map your focal } \\
\text { offer: } \\
\text {-Supply chain \& Value chain } \\
\text {-Complementors sub- } \\
\text { ecosystem } \\
\text {-Transactional platform } \\
\text {-Science (R\&D or Innovation) } \\
\text { sub-ecosystem } \\
\text {-Technologies sub-ecosystem }\end{array}$ & $\begin{array}{l}\text {-Study the actors of the sub- } \\
\text { ecosystem you need to engage } \\
\text { in. } \\
\text {-Identify the actors you need to } \\
\text { collaborate and partner with. } \\
\text {-Identify control points where } \\
\text { SME can maximize impact and } \\
\text { the owners of those control } \\
\text { points. }\end{array}$ & $\begin{array}{l}\text {-Partner with existing sub- } \\
\text { ecosystem actors to benefit } \\
\text { from their established } \\
\text { reputation. } \\
\text {-Partner and collaborate with } \\
\text { those sub-ecosystem actors } \\
\text { whose offers complement your } \\
\text { offer. } \\
\text {-Collaborate to share } \\
\text { capabilities and bridge capital } \\
\text { gap. }\end{array}$ \\
\hline
\end{tabular}

Figure 4. Process for an SME to enact MVF engagement strategy in a sub-ecosystem

or 2) a niche innovation. As a niche player developing foundational technology or products/services that complement the innovation ecosystem's focal value propositions, the SME should have a thorough expertise in a well-defined area that ties in well with the innovation ecosystem.

The identified process that will enable SMEs to enact their MVF engagement strategy consist of five steps as illustrated in Figure 4 and elaborated in the following.

1. Identify a gap in the existing ecosystem that a SME wants to engage in. To successfully engage in an ecosystem, a SME should start by identifying a subset of problems in the ecosystem and prioritize the ones that SME is better positioned to solve.

\section{Develop an offer that addresses the identified} problem. After identifying the ecosystem problem that it wants to resolve, the SME should develop an offer that addresses that problem and provide a compelling value proposition that ensures the highest level of ecosystem partners. This will enable the SME to gain competitive advantage over other SMEs that might try to address the same problem.

\section{Identify the sub-ecosystem within the ecosystem that} a SME can better engage in. To better enact its MVF ecosystem engagement strategy, the SME should choose a sub-ecosystem where it can map its focal offer in the ecosystem that it wants to engage in, by choosing among the following: i) supply chain and value chain sub-ecosystem, ii) complementors sub-ecosystem, iii) transactional platform subecosystem, iv) science (R\&D and Innovation) subecosystem, and v) technologies sub-ecosystem.

\section{Identify and study the sub-ecosystem actors that a} SME needs to partner and collaborate with. Successful sub-ecosystem engagement requires SMEs to study the actors of that sub-ecosystem and identify the ones it should strategically collaborate and partner with. For this purpose, the SME needs to identify both control points within the sub-ecosystem where it can maximize its impact and who are the owners of those points.

\section{Establish collaboration and partnership with} required sub-ecosystem actors. After identifying the sub-ecosystem actors that it needs to collaborate with, the SME needs to establish partnerships and collaborate with those actors. By collaborating with them, the SME can benefit from the ecosystem actors' expertise and experience, as well as complement or share capabilities and bridge a capital gap.

\section{Discussion and Conclusion}




\section{Strategies for a Small to Medium-sized Enterprise to Engage in an Existing}

\section{Ecosystem Ermela Bashuri and Tony Bailetti}

This article aimed to explore applicable ecosystem engagement strategies from the perspective of SMEs as discussed in previous literature on ecosystems. The findings showed that various strategies are possible for SMEs to engage in existing ecosystems. The first strategy proposed in this project was based on the theory of ecosystems as articulated by Jacobides et al. (2018). The second strategy was built based on a summative model that synthesizes the findings from the literature by several authors, which also includes the definition and classification of complementarities proposed by Jacobides et al. (2018). Both strategies suggest that SMEs should collaborate with ecosystem complementors by mapping complementarities (in production/consumption) that are unique or supermodular. Another point of similarity between these two strategies is that they emphasize the importance of collaborations and partnerships with existing ecosystem actors.

The approach suggested in the third strategy is different from the previous two strategies, as this strategy is based on Adner's (2012) concept of Minimum Viable Footprint (MVF). It recommends SMEs to strategize their engagement in an existing ecosystem by identifying the minimum configuration of ecosystem elements they need to create and commercialize a unique value proposition. Further, the strategy recommends that SMEs should start small by engaging in a sub-ecosystem of an existing ecosystem and, only in later phases, expand its ecosystem presence by collaborating with new complementors or by providing further offers that add more value to the ecosystem's focal value proposition. The comparison of the three existing ecosystem entry strategies contributes to the literature on ecosystems (see, for example, Koch \& Kerschbaum, 2014; Adner, 2017) by highlighting the differences between the strategies proposed in separate instances in the previous scholarly literature.

\section{Implications to practice}

The findings also contribute to the managerial practice of SMEs in multiple ways. The first identified ecosystem entry strategy informs SME managers that 1) complementarity, 2) modularity, 3) the role that the SME wants to play in an ecosystem, and 4) collaboration and partnerships with other ecosystem actors, are keys for successful engagement in an existing ecosystem. The second strategy suggests that, apart from the above listed four building blocks, a successful ecosystem engagement strategy requires SME managers to also consider the attributes of the ecosystem they want to engage in. The third strategy means that before entering an existing ecosystem, the SME needs to identify the MVF they need to establish in an ecosystem. To achieve this, the SME should start by engaging in a proper subecosystem of an existing ecosystem. In so doing, the small business and its managers can increase their odds of success when entering into an ecosystem for value creation.

\section{Limitations and future research avenues}

There are at least three obvious limitations in this article. First, the article only examines a subset of literature on ecosystems, by focusing on studies related to three well-known types of ecosystems, namely innovation ecosystems, platform ecosystems, and business ecosystems. Scholarly studies focusing on other, perhaps lesser known and more novel types of ecosystems, such as digital ecosystems and partner ecosystems, were not included. The replication of this research by including other types of ecosystems could extend the generalizability of the deliverables. Second, the strategies provided in this article are general by their nature and are not specific regarding each possible scenario or outcome that a SME might have through ecosystem engagement. SMEs need to tailor their ecosystem engagement strategy based on other factors that are specific to the current SME's situation, or specific to the industry and environment that the SME operates in.

Third, this article does not include any quantitative assessment of SME ecosystem engagement strategies, nor did it collect any empirical primary data to support or illustrate the ideas drawn from the scholarly literature. For example, multiple case studies, let alone quantitative assessment of the strategies, would help to validate the theoretical constructs in a real-world context. Such approaches would allow observation and clarification of how applying strategies impacts SMEs' engagement in existing ecosystems. Further, the findings from such approaches could help to enhance the strategies and customize them based on SMEs' specific characteristics. Overall, future research could expand our understanding on ecosystem engagement strategies by including more ecosystem types and collecting information from SMEs that have engaged in existing ecosystems. Further, future research could study the sequencing and prioritization of engagement strategy tasks that SMEs can follow. 


\section{Strategies for a Small to Medium-sized Enterprise to Engage in an Existing}

\section{Ecosystem Ermela Bashuri and Tony Bailetti}

\section{References}

Adner, R. 2012. The Wide Lens. Kennett Square, PA: Soundview Executive Book Summaries.

Adner, R. 2017. Ecosystem as Structure: An Actionable Construct for Strategy. Journal of Management, 43(1): 39-58.

DOI: https://doi.org/10.1177/0149206316678451

Agarwal, S., \& Kapoor, R. 2018. Two Faces of Value Creation in Platform Ecosystems: Leveraging Complementarities and Managing Interdependencies. Working paper.

Bailetti, T. 2010. Blueprint and Approach to Grow Revenue in Small Technology Companies. OpenSource Business Resource. Available at <http://timreview.ca/article/355>

Battistella, C., Colucci, K., De Toni, A.F., \& Nonino, F. 2013. Methodology of Business Ecosystems Network Analysis: A case study in Telecom Italia Future Centre. Technological Forecasting and Social Change, 80(6): 1194-1210.

DOI: https://doi.org/10.1016/j.techfore.2012.11.002

Baumann, S. 2019. Where to from Here? Conceptualizing operating strategies for platforms and business-ecosystems in smart manufacturing. Presented at: The 50th DSI Conference "Transforming Decision Sciences through Emerging Technologies", November 23-25, 2019, New Orleans, USA.

Ceccagnoli, M., Forman, C., Huang, P., \& Wu, D. J. 2012. Co-creation of Value in a Platform Ecosystem: The Case of Enterprise Software. MIS Quarterly, 36(1): 263-290.

DOI:

https://dl.acm.org/doi/10.5555/2208955.2208971

Cusumano, M.A., Gawer, A., \& Yoffie, D.B. 2019. The Business of Platforms: Strategy in the age of digital competition, innovation, and power. New York: Harper Business.

Dal Mas, F., Biancuzzi, H., Massaro, M., \& Miceli, L. 2020. Adopting a Knowledge Translation Approach in Healthcare Co-production. A case study. Management Decision, 58(9): 1841-1862.

DOI: https://doi.org/10.1108/MD-10-2019-1444

Dattée, B., Alexy, O., \& Autio, E. 2018. Maneuvering in Poor Visibility: How Firms Play the Ecosystem Game when Uncertainty is High. Academy of Management Journal, 61(2): 466-498.

DOI: https://doi.org/10.5465/amj.2015.0869

Davidson, S., Harmer, M., \& Marshall, A. 2014. The New Age of Ecosystems-Redefining Partnering in an Ecosystem Environment. Executive Report, IBM Global Business Services, IBM Institute for Business Value.

De Stobbeleir, K., Peters, C., \& Pfisterer, M. 2020. Business Ecosystems. What do they mean for your company? And how do they impact your role as a leader? White Paper, Vlerick Business School.

Doh, J.P., Tashman, P., \&Benischke, M.H. 2019. Adapting to Grand Environmental Challenges through Collective Entrepreneurship. Academy of Management Perspectives, 33(4): 450-468. DOI: https://doi.org/10.5465/amp.2017.0056

Eckhardt, J., Ciuchta, M., \& Carpenter, M. 2018. Open Innovation, Information, and Entrepreneurship within Platform Ecosystems. Strategic Entrepreneurship Journal, 12(3): 369-391.

DOI: https://doi.org/10.1002/sej.1298

Frow, P., McColl-Kennedy, J.R., Hilton, T., Davidson, A., Payne, A., \& Brozovic, D. 2014, Value Propositions: A service ecosystems perspective. Marketing Theory, 14(3): 327-351.

DOI: https://doi.org/10.1177/1470593114534346

Heikkilä, M., \& Kuivaniemi, L. 2012. Ecosystem Under Construction: An Action Research Study on Entrepreneurship in a Business Ecosystem. Technology Innovation Management Review, 2(6): 1824.

DOI: http://doi.org/10.22215/timreview/564

Heimala, P. 2020. Business Ecosystems are Creating New Business Opportunities for Asymmetric Partners. Sitra, Finland. Available at:

<https://www.sitra.fi/en/publications/businessecosystems-are-creating-new-businessopportunities-for-asymmetric-partners/\#1-changingcompetitive-situation-driving-companies-to-createecosystems $>$ [Accessed 15 February 2021].

Heising, W., Pidun, U., Krüger, T., \& Küpper, D. 2021. Additive Manufacturing Needs a Business Ecosystem. BCG. Available at: <https://www.bcg.com/enil/publications/2020/additive-manufacturing-needsto-adopt-a-managed-business-ecosystem> [Accessed 27 March 2021].

Jacobides, M.G. 2019. In the Ecosystem Economy, What's Your Strategy? Harvard Business Review, 97(5): 128-137.

Jacobides, M., Lang, N., \& Von Szczepanski, K. 2019. What Does a Successful Digital Ecosystem Look Like? BCG Global. Available at: <https://www.bcg.com/publications/2019/whatdoes-successful-digital-ecosystem-look-like> [Accessed 3 January 2021].

Jacobides, M.G., Cennamo, C., \& Gawer, A. 2018. Towards a Theory of Ecosystems. Strategic Management Journal, 39(8): 2255-2276.

DOI: https://doi.org/10.1002/smj.2904

Kapoor, R. 2018. Ecosystems: Broadening the locus of value creation. Journal of Organization Design, 7, Article 12.

DOI: https://doi.org/10.1186/s41469-018-0035-4 


\section{Strategies for a Small to Medium-sized Enterprise to Engage in an Existing}

\section{Ecosystem Ermela Bashuri and Tony Bailetti}

Kapoor, R., \& Lee, J.M. 2012. Coordinating and Competing in Ecosystems: How organizational forms shape new technology investments. Strategic Management Journal, 34(3): 274-296.

DOI: https://doi.org/10.1002/smj.2010

Koch, S., \& Kerschbaum, M. 2014. Joining a Smartphone Ecosystem: Application developers' motivations and decision criteria. Information and Software Technology, 56(11): 1423-1435.

DOI: https://doi.org/10.1016/j.infsof.2014.03.010

Leavy, B., 2012. Interview - Ron Adner: managing the interdependencies and risks of an innovation ecosystem. Strategy \& Leadership, 40(6): 14-21.

DOI: https://doi.org/10.1108/10878571211278840

Leminen, S., Turunen, T., \& Westerlund, M. 2015. The Grey Areas Between Open and Closed in Innovation Networks. Technology Innovation Management Review, 5(12): 6-18.

DOI: http://doi.org/10.22215/timreview/948

Mäkinen, S.J., \& Dedehayir, O. 2012. Business ecosystem evolution and strategic considerations: A literature review. In: 18th International ICE Conference on Engineering, Technology and Innovation. June 2012 IEEE. pp. 1-10.

DOI: https://doi.org/10.1109/ICE.2012.6297653

Marty, F.M., \& Warin, T. 2020. Keystone Players and Complementors: An Innovation Perspective. CIRANO Working Papers, 2020s-61. CIRANO. Available at: $<$ https://ideas.repec.org/p/cir/cirwor/2020s61.html>

Moore, J. 2006. Business Ecosystems and the View from the Firm. Antitrust Bulletin, 51(1): 31-75.

DOI: https://doi.org/10.1177/0003603X0605100103

Pidun, U., \& Reeves, M. 2019. Do You Need a Business Ecosystem? BCG. Available at: <https://www.bcg.com/en-ca/publications/2019/doyou-need-business-ecosystem $>$ [Accessed 27 March 2021].

Pidun, U., Reeves, M., \& Knust, N. 2020. How Do You Manage A Business Ecosystem? BCG Henderson Institute. Available at:

<https://bcghendersoninstitute.com/how-do-youmanage-a-business-ecosystem-2863f62fa044>

[Accessed 14 January 2021].

Sebastian, I.M., Weill, P., \& Woerner, S.L. 2020. Driving Growth in Digital Ecosystems. MIT Sloan Management Review, 62(1): 58-62.

Ringel, M., Grassl, F., Baeza, R., Kennedy, D., Spira, M., \& Manly, J. 2019. The Most Innovative Companies 2019: The rise of AI, platforms, and ecosystems. Boston Consulting Group.

Ritala, P., Agouridas, V., Assimakopoulos, D., \& Gies, O. 2013. Value Creation and Capture Mechanisms in Innovation Ecosystems: a comparative case study. International Journal of Technology Management, 63(3/4): 244-267.

\section{DOI: https://doi.org/10.1504/IJTM.2013.056900}

Ritala, P., Aarikka-Stenroos, L., \& Gnyawali, D.R. 2020. Co-Evolution of Ecosystem Value Proposition Across Institutional Fields: Longitudinal Case Study. In: Academy of Management Proceedings, 2020(1). DOI: https://doi.org/10.5465/AMBPP.2020.145

Rong, K., Hu, G., Hou, J., Ma, R., \& Shi, Y. 2013. Business Ecosystem Extension: facilitating the technology substitution. International Journal of Technology Management, 63(3/4): 268-294.

DOI: https://dx.doi.org/10.1504/IJTM.2013.056901

Talmar, M., Walrave, B., Podoynitsyna, K., Holmström, J., \& Romme, A. 2020. Mapping, Analyzing, and Designing Innovation Ecosystems: The Ecosystem Pie Model. Long Range Planning, 53(4), 101850.

DOI: https://doi.org/10.1016/j.lrp.2018.09.002

Tang F, \& Qian Z. 2020. Leveraging Interdependencies among Platform and Complementors in Innovation Ecosystem. PLoS One, 15(10), e0239972.

DOI:

https://dx.doi.org/10.1371/journal.pone.0239972

Tavalaei, M.M., \& Cennamo, C. 2020. In Search of Complementarities within and Across Platform Ecosystems: Complementors' relative standing and performance in mobile apps ecosystems. Long Range Planning, 101994.

DOI: https://doi.org/10.1016/j.lrp.2020.101994

Thomas, L.D., \& Autio, E. 2020. Innovation Ecosystems. Innovation Ecosystems in Management: An Organizing Typology. In: Oxford Research Encyclopaedia of Business and Management: Oxford University Press

Tiwana, A. 2014. Platform Ecosystems: Aligning Architecture, Governance, and Strategy. San Francisco: Elsevier Science \& Technology.

Van Angeren, J., Blijleven, V., Jansen, S., \& Brinkkemper, S. 2013. Complementor Embeddedness in Platform Ecosystems: The case of google apps. In: 7th IEEE International Conference on Digital Ecosystems and Technologies (DEST): 37-42.

DOI: https://dx.doi.org/10.1109/DEST.2013.6611326

Weber. L, \& Hine. J. 2015. Who Inhabits a Business Ecosystem? The Techno-species as a Unifying Concept. Technology Innovation Management Review, 5(5): 31-44.

DOI: http://doi.org/10.22215/timreview/896

Williamson, P.J., \& De Meyer, A. 2020. Ecosystem Edge: Sustaining competitiveness in the face of disruption. Stanford University Press.

Xu, G., Wu, Y., Minshall, T., \& Zhou, Y. 2018. Exploring Innovation Ecosystems across Science, Technology, and Business: A case of 3D printing in China. Technological Forecasting \& Social Change, 136: 208221.

DOI: https://doi.org/10.1016/j.techfore.2017.06.030 


\title{
Strategies for a Small to Medium-sized Enterprise to Engage in an Existing
}

\section{Ecosystem Ermela Bashuri and Tony Bailetti}

\begin{abstract}
About the Authors
Ermela Bashuri is a MEng graduate of Carleton University's TIM program. She also holds a MSc degree in European Economic Studies from the University of Tirana in Albania. Ermela is an experienced finance officer who has worked in the government, telecommunications, IT, and banking sectors. During her studies at Carleton University, Ermela held the position of Research Assistant and is currently working as a Business Analyst for Lixar IT (Lixar- BDO) in Ottawa, Canada. Her research interests include innovation ecosystems, ecommerce, and cross border trade.

Dr. Tony Bailetti holds a faculty appointment in Carleton University's Sprott School of Business and the Faculty of Engineering and Design (carleton.ca). Dr. Bailetti is the past Director of Carleton's Technology Management Innovation (TIM) program (timprogram.ca). He is the founder of the Scale Early, Rapidly and Securely community (globalgers.org) and the TIM Review (timreview.ca). $\mathrm{He}$ is the Chair of the Board of the Nigeria-Canada Trade and Investment Group (nctig.org). He is the lead for the AI for Local Value and Cross-border for Local Value, two global programs designed to scale the value of companies early and rapidly. His areas of expertise include: i) Technology entrepreneurship; ii) Scaling companies early, rapidly, and securely; and iii) Cross-border ecommerce.
\end{abstract}

Citation: Bashuri, E. and Bailetti, T. 2021. Strategies for a Small to Mediumsized Enterprise to Engage in an Existing Ecosystem Technology Innovation

Management Review, 11 (7/8): 5-19. http://doi.org/10.22215/timreview/1453

Keywords: Ecosystem, SME, Strategy, Engagement, Entry, Value creation, Complementarities 